\title{
Faculty Research Productivity in Hong Kong across Academic Discipline
}

\author{
Jisun Jung \\ Correspondence: Jisun Jung, Faculty of Education, The University of Hong Kong, Hong Kong SAR, China. Tel: \\ 852-2859-1957. E-mail: jisun@hku.hk
}

Received: November 5, 2012 Accepted: November 21, 2012 Online Published: November 28, 2012

doi:10.5539/hes.v2n4p1

URL: http://dx.doi.org/10.5539/hes.v2n4p1

\begin{abstract}
This study examines the research productivity of Hong Kong academics. Specifically, it explores the individual and institutional factors that contribute to their productivity while also comparing determinants across academic disciplines. We have conducted OLS regression analysis using the international survey data from "The Changing Academics Profession." We found that Hong Kong academics are highly internationalized in terms of research activities. Moreover, research productivity is influenced by a number of factors, including personal characteristics, workload, differences in research styles, and institutional characteristics. In addition, considerable variation exists regarding the determinants of research productivity across disciplinary categories.
\end{abstract}

Keywords: Hong Kong academics, research productivity, academic discipline, CAP data

\section{Introduction}

In recent years, there has been increasing interest among researchers and policy makers in the notion of research productivity. Research productivity is one of the major measures of university academic performance and a core indicator for calculations of university rankings. A number of studies have tried to compare research productivity across countries or academic disciplines and to explore the main factors that enhance the research productivity of faculty members (Allison \& Long, 1990; Baird, 1991; Shin \& Cummings, 2010). This study used the international survey data set from "The Changing Academic Profession" to help identify and analyze the factors enhancing the research productivity of faculty members at Hong Kong universities.

Past literature has been largely quantitative in character and groups influential factors of research productivity into two broad categories: individual-level characteristics and institutional features. No single theory yet exists that can adequately define the relationship between research productivity and a set of reliable predictors. There are many obstacles to developing a unified model that could be used to explain the varying levels of researcher productivity, for example: methodological rigor, limited empirical tests, and the effect of multiple different variables (Wood, 1990). Moreover, these studies have focused almost exclusively on western countries (especially the U.S.) to the determinant of understanding research productivity worldwide. However, it is obvious that there exists the significance of cultural heritage for the styles of knowledge production by Asian academics as well.

Higher education in Asia is approaching a historical moment, and recently, the average annual growth rates of research publications have been particularly high in Asia. For instance, the growth rates among Chinese and Korean academics were $16.8 \%$ and $10.1 \%$ in 2011. In addition, China is currently the world's second-largest national producer of science and engineering articles (National Science Foundation, 2012). Academic centers in Asia, such as Hong Kong, Singapore, Tokyo, and Seoul as well as the emergent academic centers of Beijing and Shanghai have played a pivotal role in this context. These cities tend to have a concentration of highly ranked universities in Asia with preeminence in research productivity, which increases the probability of their potential impact on research productivity to the surrounding areas (Postiglione, 2011).

Thus, this study examined the research productivity of Hong Kong academics. In doing so, we explored the individual and institutional factors that contribute to productivity and compare determinants of productivity across academic disciplines. The following questions are of particular interest to this study: What factors influence research productivity of Hong Kong academics? What are the differences of determinants of research productivity across academic disciplines? 


\section{Background: Academics in Hong Kong}

With eight universities and several other tertiary institutions, higher education plays a key role in the education system in Hong Kong. As a highly international urban center, Hong Kong's higher education institutions attract foreign academics and students from abroad. In addition, the HKUGC (University Grants Committee in Hong Kong), which directs government funding to universities, has been doing a research assessment exercise to investigate the publication outputs from individual departments among the local universities since the early 1990s. Research productivity is on the rise in Asia, and Hong Kong often leads the region in the production of refereed academic journal articles. According to annual reports from the University Grants Committee (UGC), higher education institutions in Hong Kong show high research productivity in various types of publications, and research productivity is balanced across institutions and academic disciplines (See Table 1). Furthermore, according to ISI Web of Science data, in 1999, the number of articles published in Hong Kong was 999; in 2011, this number reached 10,533 .

Table 1. Research productivity of Hong Kong academics by academic discipline

\begin{tabular}{|c|c|c|c|c|c|c|c|}
\hline & HKUST & $\mathrm{HKU}$ & City U & $\mathrm{HKBU}$ & CUHK & HKIEd & Poly U \\
\hline Biology \& Medicine & 224 & 3,858 & 125 & 154 & 2,336 & 19 & 518 \\
\hline Physical Sciences & 523 & 560 & 498 & 170 & 333 & 36 & 254 \\
\hline Engineering & 1,061 & 1,314 & 900 & 49 & 682 & 31 & 2,419 \\
\hline Humanities, Social Sciences \& Business & 344 & 2,705 & 1,103 & 1,328 & 2,138 & 968 & 1,063 \\
\hline All subject areas & 2,152 & 8,438 & 2,760 & 1,701 & 5,489 & 1,054 & 4,253 \\
\hline
\end{tabular}

(http://www.ugc.edu.hk/eng/ugc/index.htm)

Based on the rise of research productivity, three of Hong Kong's universities have been consistently ranked in the top five in Asia since 2009 (QS Asian University rankings), and two of them, the University of Hong Kong and Hong Kong University of Science and Technology, have competed with each other for the title of best university in Asia. Furthermore, three Hong Kong universities were ranked in the top 100 worldwide from 2004 to 2010. Most notably, the University of Hong Kong was ranked 18th in 2007. Other universities in Hong Kong have also been stepping up higher rankings in league table (Times Higher Education Worldwide University rankings). Although we need to speculate about theoretical and methodological arguments of ranking indicators, these results are still significant if we consider there are only eight universities in Hong Kong. Ho (1998) mentioned that pressure for efficiency and greater research output has increased in Hong Kong, and there is generally a decreasing trend in the percentages of non-productive academics. Current international comparative data reflects the average of articles in refereed journals and the proportion of academics without publication for the last three years. Table 2 reveals that Hong Kong academics report high rates of article productivity, which is less than academics in Korea but more than academics in Japan. In addition, the rate of non-publication is lower than in other countries.

Table 2. International comparison of research productivity

\begin{tabular}{|c|c|c|c|c|c|}
\hline Country & Article & Non-publication (\%) & Country & Article Average & Non-publication (\%) \\
\hline Korea & 11.6 & 1.9 & Portugal & 5.6 & 19.3 \\
\hline Hong Kong & 10.6 & 7.1 & Finland & 5.5 & 21.1 \\
\hline Japan & 9.7 & 11.3 & Norway & 5.2 & 18 \\
\hline Germany & 9.3 & 13.4 & USA & 5.0 & 26.2 \\
\hline China & 9.2 & 15.8 & Malaysia & 4.8 & 29.3 \\
\hline Italy & 8.8 & 6.2 & Brazil & 4.7 & 21.4 \\
\hline Australia & 7.3 & 11.4 & Argentina & 4.3 & 26.6 \\
\hline UK & 6.9 & 10.9 & Mexico & 3.2 & 40.7 \\
\hline Canada & 6.6 & 10.9 & South Africa & 3.0 & 28.5 \\
\hline
\end{tabular}

Source: CAP survey, 2007 
Unlike Japan and Korea, most Hong Kong academics are published in overseas English language journals (see Table 3). Internationalism is a driver for high research productivity among Hong Kong academics. Slowly, Hong Kong's internationalism has shifted away from the United Kingdom, Australia, and North America to include more academics from the Chinese mainland and a small but increasing number of top academics from every continent. Most top academics at research universities hold overseas doctorates, and many remain mobile and move to academic and administrative posts in overseas universities. The academic community remains wedded to publishing in international academic journals, most of which are produced in English. Furthermore, prominent international academic events - forums, seminars, and conferences — occur on a daily basis (Postiglione \& Jung, 2012).

Table 3. International comparison of research activities (\%)

\begin{tabular}{lccccccccccccccccccccccc}
\hline & $\mathrm{CA}$ & $\mathrm{US}$ & $\mathrm{FI}$ & $\mathrm{DE}$ & $\mathrm{IT}$ & $\mathrm{NL}$ & $\mathrm{NO}$ & $\mathrm{PT}$ & $\mathrm{UK}$ & $\mathrm{AU}$ & $\mathrm{JP}$ & $\mathrm{KR}$ & $\mathrm{HK}$ & $\mathrm{CH}$ & $\mathrm{MY}$ & $\mathrm{AR}$ & $\mathrm{BR}$ & $\mathrm{MX}$ & $\mathrm{ZA}$ \\
\hline $\begin{array}{l}\text { International } \\
\text { collaboration }\end{array}$ & 64 & 33 & 70 & 50 & 59 & 63 & 66 & 54 & 61 & 59 & 24 & 30 & $\mathbf{6 0}$ & 13 & 32 & 47 & 28 & 35 & 41 \\
\hline $\begin{array}{l}\text { Co-authored with } \\
\text { foreign colleagues }\end{array}$ & 43 & 24 & 45 & 45 & 47 & 57 & 50 & 46 & 44 & 40 & 31 & 28 & $\mathbf{4 9}$ & 3 & 27 & 29 & 19 & 28 & 21 \\
\hline $\begin{array}{l}\text { Published in a } \\
\text { foreign country }\end{array}$ & 60 & 30 & 73 & 67 & 74 & - & 78 & 77 & 58 & 57 & 42 & 53 & $\mathbf{8 6}$ & 28 & 49 & 61 & 45 & 53 & 39 \\
\hline
\end{tabular}

Source: CAP survey, 2007

- CA: Canada, US: USA, FI: Finland, DE: Germany, IT: Italy, NL: Netherlands, NO: Norway, PT: Portugal, UK: United of Kingdom, AU: Australia, JP: Japan, KR: Korea, CH: China, MY: Malaysia, AR: Argentina, BR: Brazil, MX: Mexico, ZA: South Africa

- $\quad$-: data missing

\section{Literature Review}

\subsection{Research Productivity and Its Predictors}

A number of investigations have been undertaken to explore the influence of research productivity of academics. Differences in research productivity have been explained in terms of individual background (e.g., age, gender, ambition, motivation and self-esteem) (Bellas \& Toutkoushian, 1999), previous experience (e.g., doctoral training, reputation of doctoral program, post-doc experience) (Horta, 2009; Stephan \& Ma, 2005), institutional characteristics (e.g., mission, colleagueship, governance, reward system) (Golden \& Carstensen, 1992; Keith et al., 2002), and disciplinary context (Cresswell, 1985; Shin \& Cummings, 2010).

\subsubsection{Individual Attributes}

In the explanation of research productivity among academics, researchers first look at individual-level variables, such as demographic characteristics and psychological traits. Demographics, for example, are essential to gain full understanding of the academic life of faculty members. In particular, experience has been considered one of the most important factors influencing the productivity of academics. This includes age; however, academic rank can also be used to measure an academic's level of experience. Senior professors have already accumulated a certain degree of academic capital and momentum in order to write and publish (Cole, 1979). Since tenured professors tend to publish more than non-tenured (Zhou \& Volkwein, 2004), academic seniors are more inclined to a higher level of research production than those at the lower rungs of the academic ladder.

Alternatively, some literature has focused on "career age" as a key measure. Career age is measured by years in academe after one receives advanced academic credentials, usually a doctorate. Some literature points out that journal article publication decreases with career age, which is probably due to senior academics being more likely to publish one or more books later in their career (Fabel et al., 2008). Gender also matters. Women academics publish less than their male counterparts, which might be explained in terms of women's social roles somehow impeding their research productivity (Sheehan \& Welch, 1996). However, Teodorescu (2000) objected and asserted that women scholars do not necessarily publish less than their gender counterpart.

Workload appears to influence research productivity. Workload is generally measured by the amount of time devoted to academic activity, and this time has increased as the roles of academics have become more complex and divergent. Not surprisingly, time spent teaching is negatively correlated with research productivity while 
time spent on research shows a positive correlation (Teodorescu, 2000). The amount of time required for lesson planning and the demands of courses, which often require high staff/student contact, are seen as limitations to an academic's ability to carry out research. In contrast, however, some authors have argued that the trend is in the opposite direction based on empirical data that links commitment to teaching with research productivity (Ramsden \& Moses, 1992). Thus, a devotion to teaching may not impede research output, and teaching effectiveness may actually complement research productivity (Wanner et al., 1981).

For academics teaching in graduate programs, supervision of doctoral candidates also affects research productivity. Dundar and Lewis (1998) proposed two perspectives about the relationship between graduate teaching load and research productivity. A high ratio of graduate program workload, including teaching and advisement, means that faculty members may have less time to do research. Negative opinions regarding the benefits of having research students are found more in the social sciences than in the natural sciences. However, a high ratio of graduate workload could also mean that faculty and students collaborate and conduct joint research projects and, subsequently, co-publish their results.

According to this view, larger numbers of graduate students contribute to a richer environment of scholarship. Larger numbers means more laboratory work, seminars, and research projects (Fox, 1983; Wood, 1990). This may be particularly important in fields related to science and engineering. Blackburn et al. (1978) found that faculty members who focus on teaching in graduate programs have higher productivity than those who prefer teaching undergraduates. They provided evidence that the number of academics teaching graduate students produce five or more articles over a two-year period, which is six times more than academics who teach only undergraduates. This position is aligned with that of Corcoran and Clark (1984), who suggested that students in doctoral programs enrich the research environment of their supervisors with enthusiasm and fresh ideas.

Although faculty may have different research styles, commitment to research is a common key variable in explaining research productivity. In some studies, primary commitment to research versus teaching has been found to be a determinant in research production. Academics whose interests are in research instead of teaching are more likely to be motivated in devoting themselves to research (Shin \& Cummings, 2010). There is ample evidence that collaboration is a key factor influencing research productivity, and academics that prefer independent or collaborative work tend to show differences in productivity as measured by research publication (Katz \& Martin, 1997). This may be because communication enhances productivity by providing ideas, catching errors, and promoting competition for rewards (Pelz \& Andrews, 1967). International collaboration, in particular, has shown positive impacts on the number of published articles and total number of publications (Smeby \& Try, 2005). The increase in internationally-oriented research journals has made international collaboration attractive to more academics than in the past. Finally, recent trends emphasizing multi-disciplinary research might also affect individual academics' research productivity (Trist, 1983; Younglove et al., 1999).

\subsubsection{Institutional Characteristics}

Demographics do not exist in isolation, and research productivity is "strongly affected by the social and organizational context in which they occur" (Fox, 1983). In short, institutional incentives also affect research productivity (Finkelstein, 1984). If institutional policies directly or indirectly influence research productivity, then what environmental factors stimulate and sustain research productivity?

Bland and Ruffin (1992) extracted twelve environmental factors to improve research productivity: clear goals that serve a coordinating function, research emphasis, distinctive culture, positive group climate, assertive participate governance, decentralized organization, frequent communication, accessible resources, sufficient size, age and diversity of the research group, appropriate rewards, concentration on recruitment and selection, leadership with research expertise, and skill in both initiating appropriate organizational structure and using participatory management practices. Cresswell (1986) further indicated that the culture of a department or institution has been found to be an important factor in determining the research performance of individual faculty members.

This study focused on three common institutional characteristics that contribute to faculty members' research productivity. First, performance-based management employs a reward system, including tenure, promotion, salary increments, and other financial support for faculty members based on their attaining success on concrete indicators, such as the number of publications, book awards, research grants, and other quantifiable forms of recognition. These criteria not only influence promotion decisions, but also reinforce future academic research and attract more research funds (Braxton et al., 2002; Fairweather, 1992). From the point of view of many academics, however, it remains arguable whether strict criteria improve the quality of research productivity while raising the quantity of research publications. 
Second, several studies have examined shared governance as an influential factor of productivity. The tradition of shared governance in higher education envisions a partnership between an institution and its faculty members. Faculty members must continue to work together to assess current institutional policies and identify and prioritize specific ways to improve the institution's working environment as well as each faculty members' contribution to the institution (Gappa, 2010). Pelz and Andrews (1967) concluded that a combination of organizational freedom and organizational coordination are both feasible and desirable for effective and productive performance. In a similar context, collegiality is important in the scientific community as collegial dialogue and exchange may be an impetus to research activity and involvement. Effective research units are characterized by openness and good collegial communication, while typical characteristics of poor units are isolation and personal conflicts (Smeby \& Try, 2005). Researchers belonging to consolidated teams are more productive than their colleagues in non-consolidated teams (Rey-Rocha et al., 2002).

Third, however, key traditions like academic freedom or shared governance need to be redefined to include the changes in today's diverse academic environment. Significant threats are raised by a number of recent developments influencing the behavior of institutions, including the commercialization of research and the difficulty in obtaining research funding. The pressure to generate income from research brings about involvement of commercial research activities that are not necessarily of great personal interest (McInnis, 2010).

\subsection{Academic Disciplines}

Do the impacts of these individual and institutional factors vary by discipline? It exist differences in theory and methods of research as well as basic paradigms between academic disciplines (Biglan, 1973; Becher \& Trowler, 1989). Disciplinary categories share a great deal in common with respect to the technical, social, and normative conditions of academics' work (Wanner et al., 1981). Thus, academic discipline is one of the most important variables influencing the academic activity and research productivity of academics.

Academics in humanities or social sciences show different preferences for publication. These differences are partly due to differences in publication patterns and partly due to differences in co-authorship. For instance, in the humanities and social sciences, the distribution of articles in journals and books/reports is similar; in the natural and medical sciences, scientific journals are regarded as the most appropriate output. There are large differences across academic disciplines with respect to the extent of co-authorship in scholarly publishing. Joint authorship is closely connected to teamwork in research, which is much less common in soft sciences compared to hard sciences (Kyvik, 2003). However, a number of studies on research productivity have dealt with limited samples in one or only a few scientific disciplines, making it difficult to generalize findings across disciplines (Wanner et al., 1981). It is important to separate disciplinary context to examine factors that determine research productivity of academics.

\section{Methods}

\subsection{Data}

Data in this study is from "The Changing Academic Profession" (CAP) project, which was conducted in 2007 and involved 20 academic systems, including four in Asia (Hong Kong, Japan, Korea, and Malaysia). The project examined the nature and extent of the changes experienced by the academic profession. The Hong Kong CAP data were collected through questionnaires consisting of fifty-three questions in six sections developed by the international CAP team and modified by the Hong Kong CAP team in accordance with specific characteristics of the Hong Kong higher education system.

The survey work was contracted to the Social Sciences Research Centre (SSRC) of the University of Hong Kong. A pilot study was conducted in May 2007 on the basis of which selected questions were modified before the main survey was conducted in June across eleven institutions of higher education. Preceding the survey, an article appeared in the Hong Kong press that outlined the significance of this research and noted the importance of academic staff to participate. Each institution had a senior academic who acted as the CAP affiliate and, in some cases, reminded academic staff to complete their survey questionnaire. Between June and August 2007, respondents returned their completed surveys to the SSRC. A total of over 811 questionnaires were returned. The SSRC handled data input and cleaning, and a data set and codebook were delivered to the Hong Kong CAP team in January 2008.

Respondents came from eleven higher education institutions from the fields of humanities and arts (18.8\%), social and behavioral sciences (15.7\%), medical and health related sciences $(13.5 \%)$, teacher training and education science (11.5\%), business, administration, and economics (11.0\%), physical science (9.5\%), engineering, manufacturing, construction, and architecture (8.8\%), life sciences (5.0\%), and law (1.8\%). 


\subsection{Dependent Variables}

In most studies, research productivity is measured in terms of the following variables: books, articles, citations, reports based on research grants, patents, and computer programs. It is common to measure research productivity in terms of quality or quantity of articles or by an index combining articles and books (Wanner et al., 1981). In this study, the number of articles and books (authored or edited) have been separately presented in the descriptive analysis section. However, in the second OLS regression section, research productivity was measured by a sum of journal articles, book chapters, (co-) authored books, and (co-) edited books during the period of the last three years.

\subsection{Independent Variables}

Several explanatory variables were included in our model based on a review of the literature cited earlier in this paper and the availability of data. First, demographic variables such as academics' gender and years of experience were included in the analysis to determine overall effects. Age or academic rank was not included as these variables can bring about problems of multi-collinearity with years of experience. For the statistical analysis, gender was treated as a dummy variable for which being male was assigned a value of 1 . Years of experience was estimated by the arithmetic differences between the year of the survey and the year a respondent obtained his or her doctorate.

Second, workload variables were measured by time spent teaching, time spent on research, and the percentage of instruction time spent on doctoral students. Time devoted to teaching (preparation of instructional materials and lesson plans, classroom instruction, advising students, reading and evaluating student work) and research (reading literature, writing, conducting experiments, fieldwork) were measured by the weekly hours for each activity and transformed into log variables to form standardization and to avoid excessive discrepancies in responses.

Third, research style was categorized by research preference, research collaboration, applied research, and multi-disciplinary research. Research preference and research collaboration were coded as dummy variables for which choosing research as one's focus and having experience of research collaboration were each assigned a value of 1 . Regarding applied research and multidisciplinary research, a Likert-type scale was included to assess an individual's perception on applied research and multidisciplinary research. The perception of applied research and multidisciplinary research were measured by the extent of agreement with the following items: "I characterize the emphasis of my primary research this (or the previous) academic year;" "Applied/practically-oriented," and "Multi-/interdisciplinary research."

Fourth, we used the means of the responses through factor analysis to measure institutional characteristics. A Likert-type scale was used to assess individual perception on performance-based management, commercial-oriented direction, and the participative governance of institutions. Each respondent's perception of performance-based management was measured by the extent of agreement with the following items: "In my institution, there is a strong performance orientation," and "In my institution, there is a top-down management style." Also, each respondent's perception of the commercial orientation of their institution was measured by the extent of agreement with the following claims: "My institution emphasizes commercial-orientation or applied research;" "Interdisciplinary research is emphasized at my institution," and "The pressures to raise external research funds have increased since my first appointment." In addition, each respondent's perception of participative governance of the institution was measured by the extent of agreement with the following claim: "In my institution, there is good communication between management and academics," and "There is collegiality in the decision making process." Table 4 presents independent variables and measurements. 
Table 4. Independent variables

\begin{tabular}{ll}
\hline Variables & Measurement \\
\hline $\begin{array}{l}\text { Demographics } \\
\text { Gender }\end{array}$ & $\begin{array}{l}\text { Dummy (Female=0, Male=1) } \\
\text { Continuous }\end{array}$ \\
$\quad$ Years of experience & Continuous (transformed to log.) \\
\hline $\begin{array}{l}\text { Workload } \\
\text { Time spent teaching }\end{array}$ & Continuous (transformed to log.) \\
Time spent research & Continuous \\
$\quad$ Percentage of instruction time for doctoral program & \\
\hline Research style & Dummy (teaching=0, research=1) \\
Research preference & Dummy (No=0, Yes=1) \\
Research collaboration & 5 Likert, 1 item \\
Applied research & 5 Likert, 1 item \\
Multi-disciplinary research & \\
\hline Institutional characteristics & 5 Likert, 2 items means \\
Performance based management & 5 Likert, 3 items means \\
Commercial orientation & 5 Likert, 2 items means \\
Shared governance &
\end{tabular}

\subsection{Model}

We have proposed to offer a composite model of productivity that is based on crucial individual attributes and institutional characteristics. Separate analysis was conducted for two disciplinary categories. Two subsamples were identified by aggregating specific disciplines into broad disciplinary categories: hard disciplines (natural sciences, engendering, and medical sciences) and soft disciplines (humanities, social science, law, education, and management).

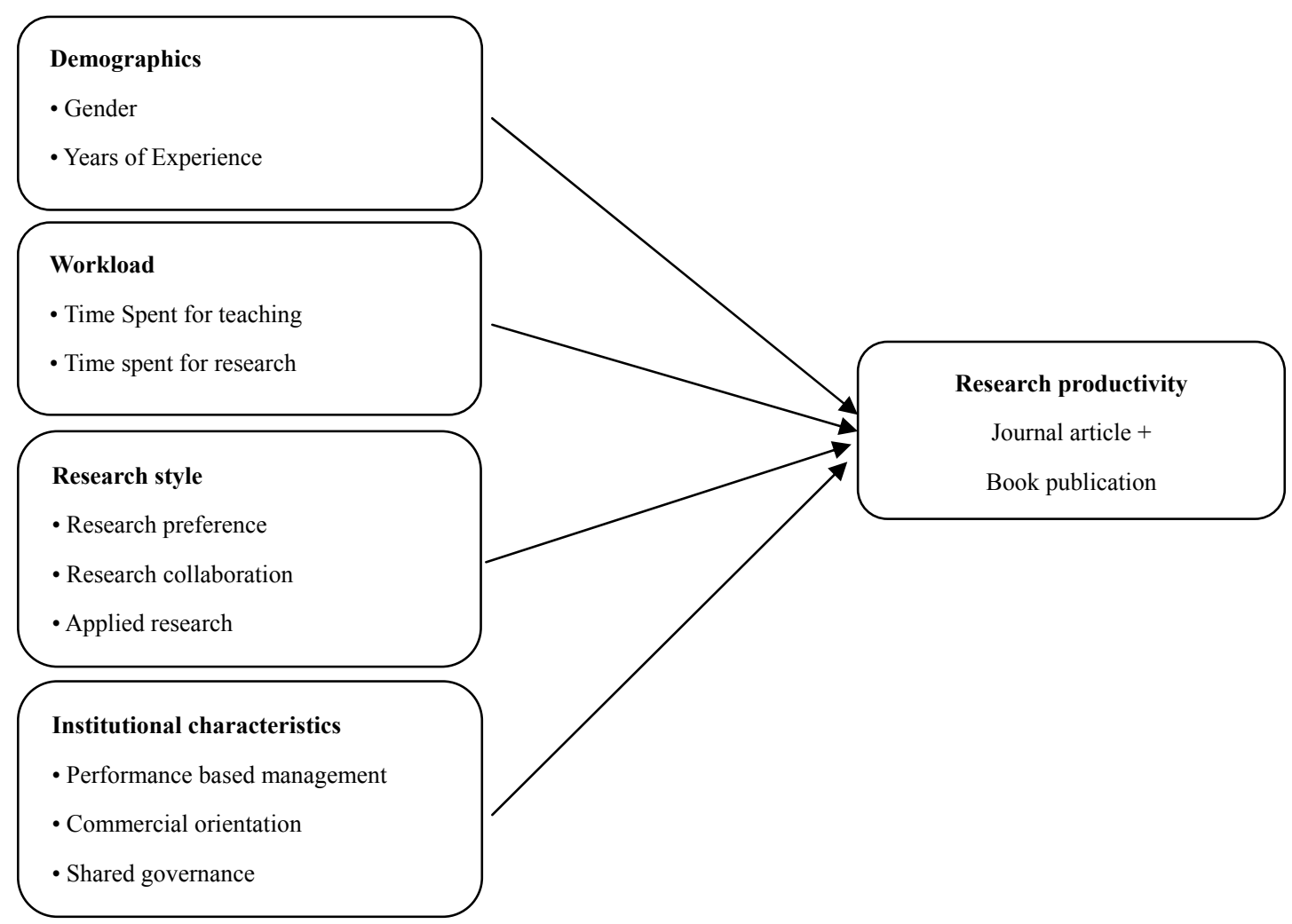

Figure 1. Research productivity and its predictors 


\section{Findings \& Discussion}

\subsection{Discrptive Statistics}

Table 5 presents the means for the productivity measures as well as the background of Hong Kong academics. We found that there are differences in research productivity according to an academic's background. The main findings are as follows.

First, in Hong Kong, male professors tend to publish more books or articles than female professors. Males also receive more research funding and present their research at more scholarly conferences. However, this can be attributed to the fact that there are many more men than women in the higher academic ranks and hard disciplines such as engineering or natural science (Ramsden, 1994).

Second, as expected, the number of publications of doctoral degree holders is higher than that of non-holders. Third, the research productivity of professors who have post-doctoral experience is higher than those who do not, particularly in the case of academic journals. A post-doctoral experience impacts positively on the research productivity of academics due, in part, to added opportunities to participate in academic exchange and network with international peers. Post-doctoral fellowships not only foster more scientific productivity later in the academic career, but also lead to a greater integration into international scholarly communities (Horta, 2009).

Fourth, senior academics tend to be more productive than junior academics. Therefore, an academic's rank correlates positively with research productivity. One possible explanation for this might be that higher ranked positions result in more opportunities to be productive due to better working conditions, invitations to write articles and book chapters, and greater overall confidence (Teodorescu, 2000).

Fifth, academics in hard disciplines (natural sciences, engineering, and medical science) publish many more journal articles than those in soft disciplines (humanities, social sciences, and business). In addition, they have the advantage of receiving more research funding as well as having more opportunities to present at scholarly conferences. However, academics in soft disciplines tend to publish more books than academics in hard disciplines.

Table 5. Research productivity of Hong Kong academics: Descriptive statistics

\begin{tabular}{|c|c|c|c|c|c|}
\hline & & $\begin{array}{c}\text { Authored or } \\
\text { co-authored } \\
\text { books }\end{array}$ & $\begin{array}{c}\text { Articled } \\
\text { published in an } \\
\text { academic journal }\end{array}$ & $\begin{array}{l}\text { Research report } \\
\text { written for } \\
\text { a funded project }\end{array}$ & $\begin{array}{c}\text { Paper presented } \\
\text { at a scholarly } \\
\text { conference }\end{array}$ \\
\hline \multirow{2}{*}{ Gender } & Male $(n=463)$ & .53 & 10.62 & 1.76 & 7.98 \\
\hline & Female $(n=202)$ & .37 & 6.79 & 1.24 & 6.22 \\
\hline \multirow{2}{*}{$\begin{array}{l}\text { Doctoral } \\
\text { degree }\end{array}$} & Yes $(n=598)$ & .48 & 9.80 & 1.72 & 7.78 \\
\hline & No $(n=56)$ & .43 & 7.37 & .70 & 5.36 \\
\hline \multirow{2}{*}{$\begin{array}{l}\text { Post-doc } \\
\text { experience }\end{array}$} & Yes $(n=56)$ & .70 & 17.18 & 2.62 & 11.20 \\
\hline & No $(n=616)$ & .46 & 8.83 & 1.51 & 7.16 \\
\hline \multirow{4}{*}{ Rank } & Full professor $(\mathrm{n}=159)$ & .65 & 15.33 & 2.01 & 11.87 \\
\hline & Associate professor $(\mathrm{n}=194)$ & .43 & 10.58 & 2.04 & 7.69 \\
\hline & Assistant professor $(\mathrm{n}=248)$ & .42 & 5.48 & 1.18 & 5.03 \\
\hline & Lecture $(n=33)$ & .09 & 3.21 & .30 & 2.21 \\
\hline \multirow{4}{*}{ Age } & Over 60’s $(\mathrm{n}=38)$ & .66 & 8.61 & .79 & 7.95 \\
\hline & 50 's $(n=210)$ & .47 & 10.80 & 1.62 & 8.47 \\
\hline & 40 's $(n=252)$ & .59 & 9.93 & 1.76 & 7.42 \\
\hline & 30's $(n=133)$ & .27 & 6.68 & 1.56 & 6.28 \\
\hline \multirow{4}{*}{ Tenured } & Permanently $(\mathrm{n}=255)$ & .55 & 13.40 & 2.21 & 9.55 \\
\hline & Continuously $(\mathrm{n}=48)$ & .29 & 9.56 & 1.27 & 5.90 \\
\hline & $\begin{array}{l}\text { Fixed term with tenure track } \\
(\mathrm{n}=199)\end{array}$ & .41 & 6.88 & 1.29 & 6.40 \\
\hline & $\begin{array}{l}\text { Fixed term with non-tenure track } \\
(\mathrm{n}=151)\end{array}$ & .48 & 6.19 & 1.21 & 5.64 \\
\hline \multirow{2}{*}{ Discipline } & Hard $(n=219)$ & .42 & 16.39 & 2.68 & 11.07 \\
\hline & Soft $(n=389)$ & .49 & 5.77 & 1.05 & 5.67 \\
\hline
\end{tabular}

\subsection{Regression Statistics}

Table 6 presents standardized and metric regression coefficients for research productivity, regressed 
demographics, workload, research style, and institutional characteristics. Separate analysis was conducted for the two disciplinary categories. Before looking at the differences across disciplines, we identified factors that might affect the total sample. First, demographics such as gender and years of experience are significant factors that predict research productivity of Hong Kong academics. Second, workload also determines research productivity to a great extent. As anticipated, time devoted to research is a positive factor, and time spent teaching is a negative factor. In addition, the more time that is devoted to teaching in a doctoral program, the higher the academic's research productivity. Third, an academic's research style also influences research productivity. This finding is consistent with the result of a recent study that showed research collaboration increases productivity (Abramo et al., 2009). It should also be noted that applied research and multidisciplinary research positively affect productivity. Fourth, while institutional characteristics such as performance-based management and commercial-orientation positively influence journal publication, participative governance has the opposite effect on publications.

The impacts of these factors vary across discipline. As expected, the pattern of values for the regression coefficient was quite different across disciplines. Statistical tests for the differences in the regression slopes across disciplines have been presented. Despite the size and heterogeneity of the sample, as well as the limitations imposed upon the model by the nature of secondary analysis, the full form regression equations in Table 6 account for considerable variance in productivity among hard disciplines (33\%) and soft disciplines $(25 \%)$.

First, gender is still an important factor to determine the research productivity of academics, particularly in hard disciplines. Second, the number of years of experience is a significant predictor of research productivity. However, experience is more important for professors in soft disciplines than those in hard disciplines. Third, the amount of weekly time devoted to research has a strong effect on productivity for academics in soft disciplines. Meanwhile, the time devoted to teaching has a significant negative effect on academics in hard disciplines. The greater the time spent on teaching, the lower the productivity; this is particularly true for academics in the hard disciplines. Fourth, research preference and research collaboration are significant only in the soft disciplines. In hard disciplines, academics preferring applied or multidisciplinary research show a higher frequency of journal publication. However, in soft disciplines, only multidisciplinary research is shown to have a positive influence on productivity. Furthermore, regarding institutional characteristics, it is interesting that academics in soft disciplines are influenced by commercial orientation. This may be attributed to a relative lack of research funding for academics in soft disciplines compared to those in hard disciplines; academics who are affiliated with abundant research budgets tend to have more opportunities to participate in research projects and to improve their productivity.

Table 6. Determinants of research productivity of Hong Kong academics: Regression statistics

\begin{tabular}{|c|c|c|c|}
\hline & Total $(n=809)$ & Hard discipline $(n=266)$ & Soft discipline $(n=454)$ \\
\hline \multicolumn{4}{|l|}{ Individual characteristics } \\
\hline Gender & $.142 * * *$ & $.176^{* *}$ & $.108 *$ \\
\hline Years of experience & $.141 * * *$ & .133 & $.157 * *$ \\
\hline \multicolumn{4}{|l|}{ Workload } \\
\hline Time spent teaching & $-.132 * * *$ & $-.192 * *$ & -.060 \\
\hline Time spent research & $.111 * *$ & .107 & $.108 *$ \\
\hline $\begin{array}{l}\text { Instruction time for } \\
\text { doctoral programs }\end{array}$ & $.141^{* * *}$ & .076 & $.146^{* *}$ \\
\hline \multicolumn{4}{|l|}{ Research style } \\
\hline Research preference & $.103 * *$ & .116 & $.102 *$ \\
\hline Collaboration & $.157 * * *$ & .017 & $.167 * *$ \\
\hline Applied & .038 & $.138^{*}$ & -.018 \\
\hline Multi-disciplinary & $.225 * * *$ & $.282 * * *$ & $.196 * * *$ \\
\hline \multicolumn{4}{|l|}{ Institutional characteristics } \\
\hline Performance-based management & .058 & $.124 *$ & .062 \\
\hline Commercial oriented & $.119^{* *}$ & .065 & $.117^{*}$ \\
\hline Shared governance & $-.113 * *$ & -.055 & -.048 \\
\hline R square & .362 & .378 & .284 \\
\hline Adjusted $\quad$ R square & .347 & .332 & .254 \\
\hline Model Fit & $\mathrm{F}=23.572 * * *$ & $\mathrm{~F}=8.167 * * *$ & $\mathrm{~F}=9.269 * * *$ \\
\hline
\end{tabular}

Standardized regression coefficient and significance $\left({ }^{*} \mathrm{p}<.000,{ }^{* *} \mathrm{p}<.01,{ }^{* * *} \mathrm{p}<.05\right)$ 


\subsection{Discussion}

Based on the findings above, we can present some noteworthy discussions. First, demographics still have a significant effect as gender and years of experience account for a good deal of the variation in research productivity. However, as Teodorescu (2000) indicated, much of the male-female productivity gap can be explained by the gender differences in variables that correlate strongly with publication productivity. For instance, women receive fewer grants than men and are employed disproportionately in disciplines with low averages for article productivity, such as humanities. Our findings were consistent with the findings from Wanner et al. (1981) that years of experience had a strong effect on academics in soft disciplines compared with smaller impacts for academics in hard disciplines. Furthermore, depending on the discipline, experience is considered to have either a negative or positive effect. For example, Lehman (1953) showed that age peak occurred earlier in abstract disciplines (such as mathematics and theoretical physics) and later in more empirically-based fields (such as geology and biology). We also expect that academics will have different peak points in their careers based on their specific fields of expertise.

Second, research productivity can be accounted for by other personal attributes, such as research style and workload. For example, the amount of time devoted to research, research preference, and research collaboration lose their preeminent importance for academics in hard disciplines. The diminished effects of these factors for research in the equation for academics in hard disciplines indicate that these dimensions are less important as determinants of publication compared to other factors. It is very popular for academics in hard disciplines to join lab-based research activities and to co-author articles. Therefore, for them, collaboration is not a key factor that can predict productivity of research journal publication. In contrast, academics in soft disciplines collaborating in research also tend to have enhanced publication records compared with academics that do not collaborate.

Third, it is interesting that the relationship between teaching and research is different depending on the academic discipline. Our study showed that the greater the time spent on teaching, the lesser the productivity, which is particularly true for academics in hard disciplines. Heavy teaching loads are generally seen as a distraction from the research enterprise, but not necessarily a pressure that lowers research output in all cases (Wood, 1990). Academics in soft disciplines tend to perceive that their teaching and research activities are compatible. This result is supported by the co-relationship between teaching and research across disciplines, confirming a widely held contention that productive scholarship does not preclude a devotion to or respect for teaching (Lewis, 1977).

Fourth, instruction time for graduate students is significant only in the soft disciplines. This result can be interpreted in terms of the strong connection between teaching and research. However, the literature also presents an opposite argument. For example, high paradigm fields, such as engineering and physical sciences, do in fact use graduate students more effectively in both teaching and research activities. On the other hand, in the social and behavioral sciences, we found that there was a significantly negative association between the ratio of graduate students to faculty and departmental research productivity (Lodahl \& Gordon, 1972).

Fifth, there needs to be a focus on the effects of multidisciplinary research. As the trend toward research collaboration among academics grows, collaboration involves researchers from multiple disciplines. Based on their collaboration, it becomes possible for academics to provide a comprehensive approach to more complex problems, which influences their productivity in a positive manner thorough synergy (Dobbs, 1987; Stark, 1995; Younglove-Webb et al., 1999). With the growth of multidiscipline/cross-discipline collaboration, team members engage in more diverse types of academic interaction, conflict resolution, and accountability.

Finally, even though there is a smaller than expected variance in institutional characteristics that predict research productivity, institutional norms remain very important. This may be helped by the fact that institutional factors are more amenable to intervention than individual characteristics. Research has shown that management patterns can be changed more easily than individual interests and attitudes (Dundar \& Lewis, 1998; Ramsden, 1994; Teodorescu, 2000). Our research showed that performance-based management is a key institutional factor that improves the research productivity of academics, particularly in hard disciplines. Thus, institutions that emphasize productivity and are highly committed to research by allocation of resources usually make promotion decisions based on measurable performance criteria (Bland \& Ruffin, 1992). This notion needs to be aligned with Pelz and Andrews (1967), who asserted that productivity can be improved when institutions provide scientists with flexibility and freedom of ideas, and where organizational goals do not conflict with individual interests and aspirations for basic research.

In this study, participative governance showed negative influence on research productivity. This is an opposite argument from previous studies. In general, participative governance and collaborative leadership are known for 
critical factors in enhancing research performance (Ramsden, 1994). Fox (1983) also said that collegial exchange may be particularly important for scholars and scientists who face conflicting demands for other-than-research performance. The culture or climate of each country and institution needs to be considered to understand these relationships in more detail.

\section{Conclusion}

This study examined the research productivity and its predictors among Hong Kong academics. The research productivity among Hong Kong academics is high compared to other higher education systems, and this study explored what factors determine this high level of productivity. Our findings indicated that research productivity is highly variable and influenced by a number of factors, including personal characteristics, workload, differences in research styles, and institutional characteristics. In addition, considerable variation exists regarding the determinants of research productivity among disciplinary categories, and there seems to be a need to further explore the importance that disciplinary contexts have on productivity. The preliminary findings identified a number of issues that are of potential relevance to university administrators interested in the development of a research policy. Universities will need to know more about how research activities and attitudes differ between disciplines and institutions.

Despite these contributions, this study has some limitations. For example, we measured research productivity by self-report, and self-reported data could fail to ascertain the relative quality of work, asking only for simple counts of articles and books. Furthermore, internal psychological characteristics, such as the intelligence, aptitude, motivation, and enthusiasm of academics are also important to understanding research productivity. We were not able to reflect on individuals' internal attributes to discuss research productivity. We suggest follow-up studies, including the examination of more diverse variables affecting research productivity and comparisons among other Asian countries.

\section{Acknowledgements}

I would like to thank Professor Gerard A. Postiglione (The University of Hong Kong) for his ideas, meaningful suggestions and comments.

\section{References}

Abramo, G., D’Angelo, C. A., \& Costa, F. D. (2009). Research collaboration and productivity: Is there correlation?. Higher Education, 57(2), 155-171. http://dx.doi.org/10.1007/s10734-008-9139-z

Allison, P. D., \& Long, S. J. (1990). Departmental effects on scientific productivity. American Sociological Review, 55(4), 469-478. http://dx.doi.org/10.2307/2095801

Baird, L. L. (1991). Publication productivity in doctoral research departments: Interdisciplinary and intradisciplinary factors. Research in Higher Education, 32(3), 303-318. http://dx.doi.org/10.1007/BF00992894

Becher, T., \& Trowler, P. R. (2001). Academic tribes and territories: Intellectual inquiry and the culture of discipline. Milton Keynes, UK: The Society for Research into Higher Education \& Open University Press.

Bellas, M. L., \& Toutkoushian, R. K. (1999). Faculty time allocation and research productivity: Gender, race, and family effects. The Review of Higher education, 22(4), 367-390. http://dx.doi.org/10.1353/rhe.1999.0014

Biglan, A. (1973). Relationships between subject matter characteristics and the structure and output of university departments. Journal of Applied Psychology, 57(3), 204-213. http://dx.doi.org/10.1037/h0034699

Blackburn, R. T., Behymer, C. E., \& Hall, D. E. (1978). Research note: Correlates of faculty publications. Sociology of Education, 51, 132-141. http://www.jstor.org/stable/2112245

Bland, C. J., \& Ruffin, M. T. (1992). Characteristics of a productive research environment: Literature Review. Academic Medicine, 67(6), 385-397. http://dx.doi.org/10.1097/00001888-199206000-00010

Braxton, J. M., Luckey, W., \& Helland, P. (2002). Institutionalizing a broader view of scholarship through Boyer's four dimensions. ASHE-ERIC Higher Education Report, 29(2).

Cole, S. (1979). Age and scientific performance. American Journal of Sociology, 84, 958-977. http://dx.doi.org/10.1086/226868

Concoran, M., \& Clark, S. M. (1984). Professional socialization and contemporary career attitudes of three faculty generations. Research in Higher Education, 20(2), 131-153. http://dx.doi.org/10.1007/BF00991464 
Cresswell, J. W. (1985). Faculty research performances: Lessons from the science and social sciences (ASHE-ERIC Higher education Report No.4). Washington, DC: Association for the Study of Higher Education

Dobbs, T. L. (1987). Toward more effective involvement of agricultural economists in multidisciplinary research and extension programs. Western Journal of Agricultural Economics, 12(1), 8-16. Retrieved from http://ageconsearch.umn.edu/bitstream/32466/1/12010008.pdf

Dundar, H., \& Lewis, D. (1998). Determinants of research productivity in higher education. Research in Higher Education, 39(6), 607-631. http://dx.doi.org/10.1023/A:1018705823763

Fabel, O., Hein, M., \& Hofmeister, R. (2008). Research Productivity in Business Economics: An Investigation of Austrian, German and Swiss Universities. German Economic Review, 9, 506-531. http://dx.doi.org/10.1111/j.1468-0475.2008.00451.x

Fairweather, J. S. (1993). Faculty reward structures: Toward institutional professional homogenization. Research in Higher Education, 34(5), 603-623. http://dx.doi.org/10.1007/BF00991922

Finkelstein, M. J. (1984). The American academic profession: A synthesis of social scientific inquiry since world war. Columbus: Ohio State University Press.

Fox, M. F. (1983). Publication productivity among scientists: A critical review. Social Studies of Science, 13(2), 285-305. http://dx.doi.org/10.1177/030631283013002005

Gappa, J. M. (2010). Rethinking faculty work and workplaces. In G. Gordon \& C. Whitchurch (Eds.), Academic and Professional Identities in Higher Education: The Challenges of a Diversifying Workforce. London: Routledge.

Golden, J., \& Carstensen, F. V. (1992). Academic research productivity, department size and organization: Further results, comment. Economics of Education Review, 11(2), 153-160. http://dx.doi.org/10.1016/0272-7757(92)90005-N

Ho, K. K. (1998). Research output among the three faculties of business, education, humanities \& social sciences in six Hong Kong universities. Higher Education, 36(2), 195-208. http://dx.doi.org/10.1023/A:1003272819743

Horta, H. (2009). Holding a post-doctoral position before becoming a faculty member: Does it bring benefits for the scholarly enterprise?. Higher Education, 58(5), 689-721. http://dx.doi.org/10.1007/s10734-009-9221-1

Katz, J. S., \& Martin, B. R. (1997). What is research collaboration?. Research Policy, 26(1), 1-18. http://dx.doi.org/10.1016/S0048-7333(96)00917-1

Keith, B., Layne, J., Babchuck, N., \& Johnson, K. (2002). The context of scientific achievement: Sex status, organizational environments, and the timing of publication on scholarship outcomes. Social Forces, 80(4), 1253-1281. http://dx.doi.org/10.1353/sof.2002.0029

Kyvik, S. (2003). Changing trends in publishing behavior among university faculty, 1980-2000. Scientometrics, 58(1), 35-48. http://dx.doi.org/10.1023/A:1025475423482

Lehman, H. C. (1953). Age and achievement. Princeton, NJ: Princeton.

Lewis, L. S. (1977). Writers of the academy unite! American Sociologist, 12, 176-181. Retrieved from http://www.jstor.org/discover/10.2307/27702296

Lodahl, G. B., \& Gordon, G. (1972). The structure of scientific fields and the functioning of university graduate departments. American Sociological Review, 37, 57-72. http://dx.doi.org/10.2307/2093493

McInnis, C. (2010). Traditions of academic professionalism and shifting academic identities. In G. Gordon \& C. Whitchurch (Eds.), Academic and Professional Identities in Higher Education: The Challenges of a Diversifying Workforce. London: Routledge.

National Science Foundation. (2012). Science and engineering indicators 2012: Academic research and development. Retrieved from http://www.nsf.gov/statistics/seind12/c5/c5h.htm

Pelz, D. C., \& Andrews, F. M. (1967). Scientists in organizations: Productive climates for research and development. New York: John Wiley and Sons.

Postiglione, G. (2011). Establishing a research university: The case of the Hong Kong University of Science and Technology. In P. G. Altbach \& J. Salmi (Eds.), The road to academic excellence: The Making of World-Class Research Universities. Washington DC: World Bank. 
Postiglione, G., \& Jung, J. (in press). Government frameworks for creating world-class universities: The Hong Kong Case. In J. C. Shin \& B. Kehm (Eds.), Institutionalization of a World-Class University in Global Competition.

QS-Asian University Rankings. (2012). Asian University rankings 2005-2012. Retrieved from http://www.topuniversities.com/university-rankings/asian-university-rankings/2012

Ramsden, P. (1994). Describing and explaining research productivity. Higher Education, 28(2), 207-226. http://dx.doi.org/10.1007/BF01383729

Ramsden, P., \& Moses, I. (1992). Associations between research and teaching in Australian higher education. Higher Education, 23(3), 273-295. http://dx.doi.org/10.1007/BF00145017

Rey-Rocha, J., Martin-Sempere, M. J., \& Garzon, B. (2002). Research productivity of scientists in consolidated vs. non-consolidated teams: The case of Spanish university geologists. Scientometrics, 55(1), 137-156. http://dx.doi.org/10.1023/A:1016059222182

Sheehan, B. S., \& Welch, A. R. (1996). The Australian academic profession. In P. G. Altbach (Ed.), The international academic profession: Portraits of fourteen countries. San Francisco, CA: Jossey-Bass Publishers.

Shin, J. C., \& Cummings, W. K. (2010). Multi-level analysis of academic publishing across discipline: Research performance, collaboration, and time on research. Scientometrics, 85(2), 582-594. http://dx.doi.org/10.1007/s11192-010-0236-2

Smeby, J. C., \& Try, S. (2005). Departmental contexts and faculty research activity in Norway. Research in Higher Education, 46(6), 593-619. http://dx.doi.org/10.1007/s11162-004-4136-2

Stark, C. R. (1995). Adopting multidisciplinary approaches to sustainable agriculture research: Potentials and pitfalls. American Journal of Alternative Agriculture, 10(4), 180-183. http://dx.doi.org/10.1017/S0889189300006445

Stephan, P. E., \& Ma, J. (2005). The increased frequency and duration of the post-doctoral career stage. The American Economic Review, 95(2), 71-75. http://dx.doi.org/10.1257/000282805774669619

Teodorescu, D. (2000). Correlates of faculty publication productivity: A cross-national analysis, Higher Education, 39(2), 201-222. http://dx.doi.org/10.1023/A:1003901018634

Thomson Reuters. (2007). Times Higher Education World University Rankings. Retrieved from http://www.timeshighereducation.co.uk/story.asp? storyCode $=421375 \&$ sectioncode $=26$

Trist, E. (1983). Referent organizations and the development of inter organizational domains. Human Relations, 36, 247-268. http://dx.doi.org/10.1177/001872678303600304

University Grants Committee (UGC) Hong Kong. (2007). Annual statistics of research performance. Retrieved from http://www.ugc.edu.hk/eng/ugc/index.htm

Wanner, R. A., Lewis, L. S., \& Gregorio, D. I. (1981). Research productivity in academic: A comparative study of the Sciences, Social Sciences and Humanities. Sociology of Education, 54(4), 238-253. http://dx.doi.org/10.2307/2112566

Wood, F. (1990). Factors influencing research performance of university academic staff. Higher Education, 19(1), 81-100. http://dx.doi.org/10.1007/BF00142025

Younglove-Webb, J., Gray, B., Abdalla, C. W., \& Thurow, A. P. (1999). The Dynamics of Multidisciplinary Research Teams in Academia. The Review of Higher Education, 22(4), 425-440. http://dx.doi.org/10.1353/rhe.1999.0019

Zhou, Y., \& Volkwein, J. F. (2004). Examining the influences on faculty department intentions: A comparison of tenured versus non-tenured faculty at research universities using NSOPF-99. Research in Higher Education, 45(2), 139-176. http://dx.doi.org/10.1023/B:RIHE.0000015693.38603.4c 